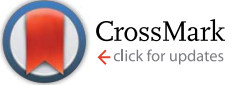

Cite this: Chem. Sci., 2016, 7, 7087

\title{
Photochemical pump and NMR probe to monitor the formation and kinetics of hyperpolarized metal dihydrides $\uparrow$
}

\author{
Barbara Procacci, ${ }^{a b}$ Pedro M. Aguiar, ${ }^{b}$ Meghan E. Halse, ${ }^{\text {ab }}$ Robin N. Perutz ${ }^{\star b}$ \\ and Simon B. Duckett ${ }^{\star a b}$
}

On reaction of $|r|(C O)\left(\mathrm{PPh}_{3}\right)_{2} 1$ with para-hydrogen $\left(p-\mathrm{H}_{2}\right), \operatorname{Ir}(\mathrm{H})_{2} \mathrm{l}(\mathrm{CO})\left(\mathrm{PPh}_{3}\right)_{2} 2$ is formed which exhibits strongly enhanced ${ }^{1} \mathrm{H}$ NMR signals for its hydride resonances. Complex 2 also shows similar enhancement of its NMR spectra when it is irradiated under $p-\mathrm{H}_{2}$. We report the use of this photochemical reactivity to measure the kinetics of $\mathrm{H}_{2}$ addition by laser-synchronized reactions in conjunction with NMR. The single laser pulse promotes the reductive elimination of $\mathrm{H}_{2}$ from $\operatorname{Ir}(\mathrm{H})_{2} \mathrm{l}(\mathrm{CO})\left(\mathrm{PPh}_{3}\right)_{2} 2$ in $\mathrm{C}_{6} \mathrm{D}_{6}$ solution to form the 16 -electron precursor 1 , back reaction with $p-\mathrm{H}_{2}$ then reforms 2 in a well-defined nuclear spin-state. The build up of this product can be followed by incrementing a precisely controlled delay $(\tau)$, in millisecond steps, between the laser and the NMR pulse. The resulting signal vs. time profile shows a dependence on $p-\mathrm{H}_{2}$ pressure. The plot of $k_{\text {obs }}$ against $p-\mathrm{H}_{2}$ pressure is linear and yields the second order rate constant, $k_{2}$, for $\mathrm{H}_{2}$ addition to 1 of $(3.26 \pm 0.42) \times$ $10^{2} \mathrm{M}^{-1} \mathrm{~s}^{-1}$. Validation was achieved by transient-UV-vis absorption spectroscopy which gives $k_{2}$ of $(3.06 \pm 0.40) \times 10^{2} \mathrm{M}^{-1} \mathrm{~s}^{-1}$. Furthermore, irradiation of a $\mathrm{C}_{6} \mathrm{D}_{6}$ solution of 2 with multiple laser shots, in conjunction with $p-\mathrm{H}_{2}$ derived hyperpolarization, allows the detection and characterisation of two minor reaction products, $2 \mathrm{a}$ and 3 , which are produced in such low yields that they are not detected without hyperpolarization. Complex $2 \mathrm{a}$ is a configurational isomer of 2 , while 3 is formed by substitution of $\mathrm{CO}$

by $\mathrm{PPh}_{3}$.

Received 4th May 2016

Accepted 3rd August 2016

DOI: $10.1039 / \mathrm{c} 6 \mathrm{sc0} 01956 \mathrm{k}$

www.rsc.org/chemicalscience

\section{Introduction}

A number of pump-probe time-resolved techniques have been developed that allow chemical reactions that happen on extremely fast timescales (milliseconds down to femtoseconds) to be followed and understood. Whilst various probe methods have been successfully exploited, ${ }^{\mathbf{1 - 4}}$ the level of structurally diagnostic information available is often limited compared to that provided by nuclear magnetic resonance (NMR). Therefore, the corresponding time-resolved NMR spectroscopy method would be a very powerful analytical tool capable of providing complementary structural and kinetic information. The existing sensitivity limitation of NMR spectroscopy would, however, need to be overcome in order to achieve this aim. paraHydrogen $\left(p-\mathrm{H}_{2}\right)$ induced polarization (PHIP) provides the

${ }^{a}$ Centre for Hyperpolarisation in Magnetic Resonance, Department of Chemistry, York Science Park, University of York, Heslington, York, YO10 5NY, UK. E-mail: simon. duckett@york.ac.uk

${ }^{b}$ Department of Chemistry, University of York, Heslington, York YO10 5DD, UK. E-mail: robin.perutz@york.ac.uk

$\dagger$ Electronic supplementary information (ESI) available: Experimental details; synthesis and characterisation of compounds, photochemical experiments, kinetic data, UV-vis data. See DOI: 10.1039/c6sc01956k necessary increase in sensitivity and the benefit of enhancement of resonances that often allow structure determination.,

We recently described a laser pump-NMR probe technique in which the laser initiation of a reaction is synchronized to NMR detection, such that NMR spectra can be recorded at welldefined intervals after a laser pulse (Fig. 1). In this method, $p-\mathrm{H}_{2}$ hyperpolarization $^{5,6}$ enhances the sensitivity of the NMR detection method so much that the dihydride complexes can be observed in optically dilute solutions with a single NMR scan at intervals as short as $10 \mu \mathrm{s}$ after the laser pulse. When dihydrogen addition is very fast, the magnetisation that is created through the use of $p-\mathrm{H}_{2}$ evolves coherently during the welldefined interval $\tau$ such that sinusoidal oscillations can subsequently be detected through radio frequency excitation. These oscillations have periods corresponding to the frequency difference between the inequivalent hydrides and/or their difference in spin-spin coupling to a heteronucleus such as phosphorus. $^{7}$ Notably, the laser method generates the hyperpolarized molecules synchronously unlike the usual PHIP methods which are inherently asynchronous. ${ }^{\mathbf{8 9}}$ We now wish to validate the method for the measurement of chemical reaction kinetics on timescales where these initial oscillations are dephased, but short enough that substantial para-hydrogeninduced-polarization (PHIP) is retained despite the effects of 

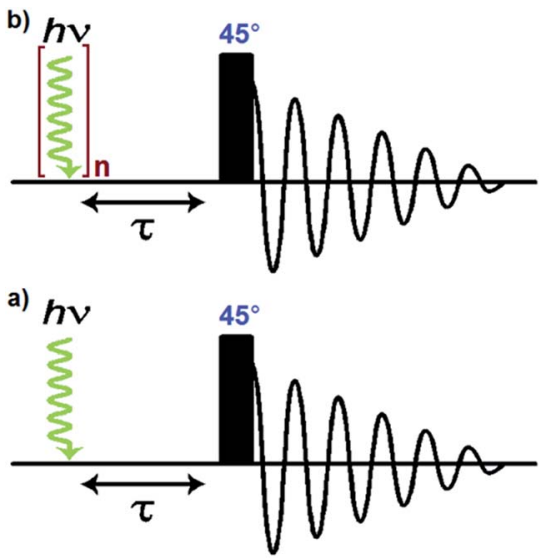

Fig. 1 Pulse sequences used in the laser pump-NMR probe experiments. (a) In the single-shot experiments, a single laser pulse (5 ns) is followed by a delay $(\tau)$ for evolution of the chemical system before observation is achieved through the application of a $45^{\circ} \mathrm{RF}$ pulse. (b) The multiple laser pulse experiments apply a train of laser pulses, separated by an additional delay of 100 ms between each of the $n$ pulses.

relaxation. The method we illustrate involves a degenerate reaction, where $\mathrm{H}_{2}$ is photodissociated from the parent and $p$ $\mathrm{H}_{2}$ adds to reform the same molecule but now in a defined nuclear spin state (indicated by asterisk, eqn (1)). In our experiments, $p-\mathrm{H}_{2}$ addition occurs in the high magnetic field of the spectrometer, a situation sometimes referred to as PASADENA conditions. ${ }^{5,8}$
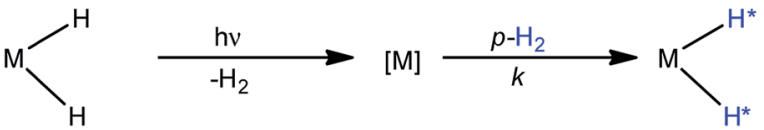

In order to validate the proposed kinetic measurements, the rate of reaction of the intermediate $[\mathrm{M}]$ with $\mathrm{H}_{2}$ must be known already (or be capable of independent measurement) and ideally have a pseudo first-order rate constant of $c a .0 .1$ to $10 \mathrm{~s}^{-1}$ at 3 bar $\mathrm{H}_{2}$ to satisfy the NMR criteria above. The thermal reactions of these complexes with $p-\mathrm{H}_{2}$ should also be understood. For this purpose, we selected $\operatorname{Ir}(\mathrm{H})_{2} \mathrm{I}(\mathrm{CO})\left(\mathrm{PPh}_{3}\right)_{2}$ 2, derived from the iodide analogue of Vaska's complex, $\operatorname{IrI}(\mathrm{CO})\left(\mathrm{PPh}_{3}\right)_{2}$ 1, for which kinetic data for reaction with dihydrogen ${ }^{10-12}$ and underlying reactivity are known. ${ }^{13-15}$ Complex 2 can be readily prepared by thermal reaction of the $\mathrm{d}^{8}$ squareplanar precursor $\operatorname{IrI}(\mathrm{CO})\left(\mathrm{PPh}_{3}\right)_{2} 1$ with $\mathrm{H}_{2}$ in $\mathrm{C}_{6} \mathrm{D}_{6}$ solution. ${ }^{16}$

The steady state photochemistry of $\operatorname{Ir}(\mathrm{H})_{2} \mathrm{X}(\mathrm{CO})\left(\mathrm{PPh}_{3}\right)_{2}(\mathrm{X}=$ $\mathrm{Cl}, \mathrm{I})$ complexes has been reported $\left(366 \mathrm{~nm}, \mathrm{C}_{6} \mathrm{H}_{6}\right)$ previously and shown to access their $\operatorname{Ir}(\mathrm{I})$ counterparts by reductive elimination of $\mathrm{H}_{2}$, which then undergo oxidative addition of $\mathrm{H}_{2}$ to reform the parent dihydride. ${ }^{15}$ In this context, the photochemical reductive elimination step allows access to its thermal microscopic reverse, oxidative addition, in a controlled way. While time-resolved spectroscopy has been used to examine these chloride complexes, the literature is not definitive on the primary photo-process. Measurements by time resolved UV-vis spectroscopy on solutions of $\operatorname{IrCl}(\mathrm{CO})\left(\mathrm{PPh}_{3}\right)_{2}$ and $\operatorname{IrCl}(\mathrm{H})_{2^{-}}$ $(\mathrm{CO})\left(\mathrm{PPh}_{3}\right)_{2}\left(\lambda_{\text {exc }}>254 \mathrm{~nm}\right.$, flash lamp) suggest $\mathrm{CO}$ photodissociation as a primary step ${ }^{17}$ while time resolved IR spectroscopy ( $\lambda_{\text {exc }}=308 \mathrm{~nm}$, laser) excludes any loss of CO on the basis of a lack of evidence for the bleaching of the parent $\mathrm{CO}$ stretch. ${ }^{18}$ Both studies detected a short-lived transient $(\sim 10 \mu \mathrm{s})$ which was speculated to be a dimeric species. Studies on the thermal addition of $p-\mathrm{H}_{2}$ to a series of related complexes, $\left(\operatorname{IrCl}(\mathrm{CO})\left(\mathrm{PPh}_{3}\right)_{2}\right.$ and $\left.\mathrm{RhCl}(\mathrm{CO})\left(\mathrm{PPh}_{3}\right)_{2}\right)$ have been previously reported. ${ }^{19,20}$ These experiments yielded large PHIP enhancements for the iridium and rhodium dihydride products visible for tens of minutes, hence demonstrating the reversibility of $\mathrm{H}_{2}$ addition and permitting signal averaging. Using both theoretical and experimental approaches, Bargon assessed the purity of the singlet state that is created between the hydride ligands of $\operatorname{IrCl}(\mathrm{H})_{2}(\mathrm{CO})\left(\mathrm{PPh}_{3}\right)_{2}$ upon the addition of $p-\mathrm{H}_{2}$ as greater than $50 \% .{ }^{21}$ In the case of $\operatorname{IrCl}(\mathrm{CO})\left(\mathrm{PPh}_{3}\right)_{2}$, thermal reaction studies demonstrated that a minor cis-cis isomer of $\operatorname{IrCl}(\mathrm{H})_{2}(\mathrm{CO})\left(\mathrm{PPh}_{3}\right)_{2}$ can be detected in addition to the more usual trans-cis product. ${ }^{22,23}$ In contrast, for derivatives of $\operatorname{RhCl}(\mathrm{CO})\left(\mathrm{PPh}_{3}\right)_{2}$, a series of binuclear products were detected which contain either bridging or terminal hydride or halide ligands. These products were proposed to form via CO loss from $\mathrm{M}(\mathrm{H})_{2}$ $\mathrm{X}(\mathrm{CO})\left(\mathrm{PPh}_{3}\right)_{2}[\mathrm{X}=$ halide $]$ with the result that a 16-electron $\mathrm{M}(\mathrm{H})_{2} \mathrm{X}\left(\mathrm{PPh}_{3}\right)_{2}$ species is created. The presence of this intermediate was confirmed by trapping with added phosphine in a series of experiments which revealed that $\operatorname{IrCl}(\mathrm{H})_{2}\left(\mathrm{PPh}_{3}\right)_{2}$ exhibits a square pyramidal geometry. ${ }^{20}$ Furthermore, extensive studies on $\operatorname{IrX}(\mathrm{CO})(\mathrm{dppe})$ have been reported establishing that dihydrogen adds to these complexes in a stereoselective way controlled by the $\mathrm{X}$ and the $\mathrm{CO}$ ligands. ${ }^{24}$

In this work, we report the investigation of the thermal and photochemical reactions of $\operatorname{IrI}(\mathrm{CO})\left(\mathrm{PPh}_{3}\right)_{2} \quad \mathbf{1}$ and $\operatorname{Ir}(\mathrm{H})_{2}{ }^{-}$ $\mathrm{I}(\mathrm{CO})\left(\mathrm{PPh}_{3}\right)_{2} 2$ in the presence of $p-\mathrm{H}_{2}$. We use our laser pumpNMR probe method to determine the kinetics of reaction of 2 with $\mathrm{H}_{2}$ and compare with the results of laser flash photolysis with UV-vis detection.

\section{Experimental}

Complex 1 was prepared using the procedure reported in the literature. ${ }^{10}$ Complex 2 was obtained by hydrogenation of 1 at 50 ${ }^{\circ} \mathrm{C}$ and complete conversion to the 18-electron dihydride was established from NMR spectra recorded at $298 \mathrm{~K} . p-\mathrm{H}_{2}$ was generated by cooling hydrogen gas over charcoal in a copper block at $26 \mathrm{~K}$. The proportion of $p-\mathrm{H}_{2}$ at $26 \mathrm{~K}$ was calculated as $>99 \%$. Pressures of $p-\mathrm{H}_{2}$ were measured with an MKS Baratron capacitance manometer. All NMR spectra were recorded on a Bruker Avance II $600 \mathrm{MHz}$ spectrometer with a $14 \mathrm{~T}$ widebore magnet fitted with a $5 \mathrm{~mm}$ BBO probe. In situ laser photolysis was carried out with a pulsed Nd:YAG laser (Continuum Surelite II) fitted with a frequency tripling crystal (output $355 \mathrm{~nm}$ ). Operating conditions were typically: $10 \mathrm{~Hz}$ repetition rate, flash lamp voltage $1.49 \mathrm{kV}$, and Q-switch delay increased from the standard to $320 \mu$ s yielding a laser power of $75 \mathrm{~mW}$ in internal mode. The energy of a single laser pulse was measured using an energy meter calibrated for $355 \mathrm{~nm}$ to be $\sim 29.8 \mathrm{~mJ}$ at our 
operating conditions (external triggering with Q-switch delay set to $150 \mu \mathrm{s})$. The unfocused laser beam is directed at the base of the spectrometer and reflected up into the probe via a mirror as previously reported. ${ }^{7}$ Adjustment screws control the vertical and horizontal position of the mirror which is on a kinematic mount. The system is fully shielded from the operator and the screws of the kinematic mount can be adjusted remotely. The laser radiation is incident on a fixed mirror that is level with the sample and passes through a hole in the probe onto the NMR tube. Standard NMR tubes fitted with Young's taps were used. The samples contained 1-2 mg of compound $\left(\mathrm{Abs}_{355} \sim 0.7\right)$ and approximately $0.4 \mathrm{~mL}$ of solvent. A sample of $\mathrm{Ru}(\mathrm{dppe}){ }_{2} \mathrm{H}_{2}$ in $\mathrm{C}_{6} \mathrm{D}_{6}$ was used for laser alignment with $p-\mathrm{H}_{2}$ amplification in real time. Standard NMR pulse sequences were modified for use with $p-\mathrm{H}_{2}$ by including a synchronized laser initiation sequence prior to NMR excitation. A purpose-written program was used to control the laser firing from the NMR console with the laser set on external triggering. The program sets the laser to fire one warm-up shot before the fire signal. The NMR pulse is initiated at a set delay time $(\tau)$ following the fire signal. The intrinsic time delay between sending the fire signal from the spectrometer and the actual firing of the laser pulse was measured with a photodiode and an oscilloscope to be $150 \mu \mathrm{s}$ (equal to the Q-switch delay for the generation of the pulse). This signal delay was incorporated into the pulse sequence such that synchronized measurements with a time delay, $\tau$, were achieved by setting the spectrometer delay to: $\tau+150 \mu \mathrm{s}$. The precision of this delay between the laser and radio frequency (RF) pulses is controlled by the $200 \mathrm{~ns}$ clock of the spectrometer.

The samples for laser flash photolysis (LFP) were prepared exclusively in a nitrogen glove box. It was loaded into a quartz cuvette (10 mm path-length) fitted with a J-Young's PTFE stopcock, a degassing bulb, and a greaseless Young's connection. The complex was dissolved in benzene $(5 \mathrm{~mL})$ with a concentration selected to have an absorbance at the laser wavelength $(355 \mathrm{~nm}$ ) between 0.6 and 0.85 . The solution was then degassed by repeated freeze-pump-thaw cycles (3 times) on a highvacuum Schlenk line before being backfilled with hydrogen. For high pressure work the window edges of the cuvette were flamed to secure the seal and the Young's connection was replaced by a glass-to-metal seal and a Swagelok ${ }^{\mathrm{TM}}$ fitting. The gas was admitted on a high pressure line and the pressure measured with an MKS Baratron capacitance manometer. The cell was held in a metal container for safety. A single sample was used for each run with increasing gas pressure. Hydrogen was of Research Grade N5.5 (BOC).

The LFP apparatus was previously described.$^{25}$ Briefly, it consists of an Nd:YAG laser (Quanta Ray, GCR3-30) operating at $355 \mathrm{~nm}$ as the exciting source, coupled to an Applied Photophysics laser kinetic spectrometer with a Xe arc lamp as a white light source. The unfocused laser beam is directed at $90^{\circ}$ to the sample. The laser runs at $30 \mathrm{~Hz}$ with individual pulses ( $c a .5 \mathrm{~ns}$ ) selected with a synchronised shutter. Light falling on the photomultiplier detector is sampled by a Tektronix TDS 540B oscilloscope. Transient decays are usually analysed as 35 shot averages. The samples were maintained at $295 \mathrm{~K}$.

\section{Results and discussion}

When $\operatorname{IrI}(\mathrm{CO})\left(\mathrm{PPh}_{3}\right)_{2} 1$ reacts with normal $\mathrm{H}_{2}$ at $298 \mathrm{~K}$ only two signals $(1: 1)$ are observed in the hydride region of the corresponding ${ }^{1} \mathrm{H}$ NMR spectrum due to a pair of chemically inequivalent hydride ligands. They resonate at $\delta-8.5$ (dt, with ${ }^{2} J_{\mathrm{HH}}=4.0 \mathrm{~Hz}$ and ${ }^{2} J_{\mathrm{PH}}=17.2 \mathrm{~Hz}$ ) for the site trans to $\mathrm{CO}$ and $\delta-14.9$ (dt, with ${ }^{2} J_{\mathrm{HH}}=4.0 \mathrm{~Hz}$ and ${ }^{2} J_{\mathrm{PH}}=13.8 \mathrm{~Hz}$ ) for the site trans to I (Fig. 2a and b). This product is therefore readily assigned as dihydride 2 . When the same reaction is repeated with $p-\mathrm{H}_{2}$ at $298 \mathrm{~K}$, these two hydride resonances exhibit strong PHIP signals (SNR $\sim 700$ on a $5 \mathrm{mg}$ solution, SNR $\sim 280$ on an optically dilute solution) and ${ }^{2} J_{\mathrm{HH}}$ is confirmed to be negative ${ }^{26}$ (see ESI $\dagger$ ). At $263 \mathrm{~K}$, very little PHIP (SNR $\sim 2.2$ on an optically dilute solution at $273 \mathrm{~K}$ with a single scan) is observed for the hydride resonances of $\mathbf{2}$ due to slow addition and no evidence for its minor cis-cis isomer was evident in ${ }^{1} \mathrm{H}$ NMR spectra even at low temperature.

When a sample of the pure dihydride $\operatorname{Ir}(\mathrm{H})_{2} \mathrm{I}(\mathrm{CO})\left(\mathrm{PPh}_{3}\right)_{2}(2)$ was examined by ${ }^{1} \mathrm{H}$ NMR spectroscopy at $298 \mathrm{~K}$ under $p-\mathrm{H}_{2}(3$ bar), no $p$ - $\mathrm{H}_{2}$-enhanced hydride resonances were observed either with the standard PHIP protocol $\left(45^{\circ}\right.$ pulse) or with the OPSY approach, ${ }^{27}$ thereby confirming its stability with respect to $\mathrm{H}_{2}$ loss on the time scale of these measurements. However, at temperatures of $335 \mathrm{~K}$ and above, PHIP-enhanced hydride resonances of 2 were observed, indicating that the thermal exchange of $\mathrm{H}_{2}$ now becomes accessible.

In contrast to this situation, upon photo-initiation by a single laser shot at $355 \mathrm{~nm}\left(298 \mathrm{~K}, 3\right.$ bar $\left.p-\mathrm{H}_{2}\right)$, the same two hydride resonances are seen with large PHIP (SNR 280) in a single scan ${ }^{1} \mathrm{H}\left\{{ }^{31} \mathrm{P}\right\}$ NMR measurement that is recorded after a $45^{\circ}$ RF pulse (Fig. 2c and Scheme 1).

The nuclear spin state description of the two hydride ligands in $2^{*}$, formed after $p-\mathrm{H}_{2}$ addition, reflects a longitudinal two spin order term $\left(\mathrm{I}_{z} \mathrm{~S}_{z}\right)$ which depends on $\sin 2 \theta$ (where $\theta$ is the pulse angle) and is therefore optimally encoded for detection by a $45^{\circ}$ pulse. ${ }^{9}$ This contrasts with the situation that was reported when the very rapid $\mathrm{H}_{2}$ addition to $\left[\mathrm{Ru}(\mathrm{CO})\left(\mathrm{PPh}_{3}\right)_{3}\right]$ was

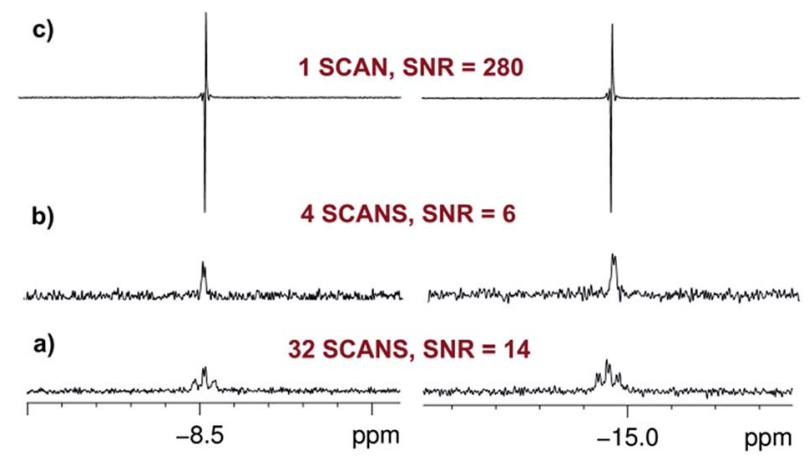

Fig. 2 Hydride region of a series of ${ }^{1} \mathrm{H}$ NMR spectra of 2 in $\mathrm{C}_{6} \mathrm{D}_{6}$ where: (a) the signals are fully relaxed prior to collection (32 scans, SNR $=14$ ); (b) the relaxed signals are ${ }^{31} \mathrm{P}$ decoupled ( 4 scans, $\mathrm{SNR}=6$ ) and (c) the signals are hyperpolarized and ${ }^{31} \mathrm{P}$ decoupled (1 laser pulse, 1 scan, SNR $=280$ ). The values of SNR in (b) and (c) yield an enhancement factor of 93. 


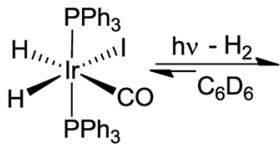

2

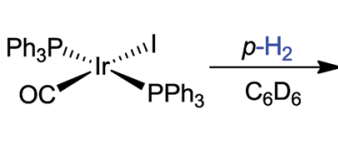

1

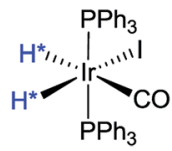

$\mathbf{2}^{*}$
Scheme 1 Photochemical reaction to prepare 2 in a hyperpolarized state, $2^{*}$.

followed. In this latter case, the original singlet state was retained $\left(\mathrm{I}_{z} \mathrm{~S}_{z}+\mathrm{ZQ}_{x}\right)$ and a $90^{\circ}$ probe pulse allowed the monitoring of the evolution of the resulting zero-quantum coherences $\left(Z_{y}\right)^{7}{ }^{7}$ This different behaviour arises because the relatively slow $\mathrm{H}_{2}$ addition to the $\left[\operatorname{IrI}(\mathrm{CO})\left(\mathrm{PPh}_{3}\right)_{2}\right], \mathbf{1}$, causes the zero quantum terms (ZQ) to lose coherence while the longitudinal two-spin order term $\left(\mathrm{I}_{z} \mathrm{~S}_{z}\right)$ is preserved. ${ }^{\mathbf{8}, \mathbf{9}}$ The resulting $\mathrm{I}_{z} \mathrm{~S}_{z}$ amplitude accumulates as the reaction proceeds until all of the intermediate 1 is converted into $\operatorname{Ir}(\mathrm{H})_{2} \mathrm{I}(\mathrm{CO})\left(\mathrm{PPh}_{3}\right)_{2}(2) .{ }^{9}$

The intensity of the hyperpolarized single scan ${ }^{1} \mathrm{H}\left\{{ }^{31} \mathrm{P}\right\}$ NMR signal in this photochemical experiment allows us to work with an optically dilute solution $\left(0.7 \mathrm{mM}\right.$ in $\mathrm{C}_{6} \mathrm{D}_{6}, \mathrm{Abs}_{(355)} \approx 0.7$ across the $5 \mathrm{~mm}$ NMR tube) whilst still obtaining a good hydride resonance signal-to-noise ratio ( $\mathrm{SNR}=280)$. It might be expected that this dilution ensures that a constant amount of $p-\mathrm{H}_{2}$ is available in solution even if multiple observations are required. However, a control measurement showed that the detected signal intensities decreased slightly after four single laser shot experiments. We therefore refreshed the dissolved $p-\mathrm{H}_{2}$ by removing the sample from the magnet/probe and reequilibrating it with the $p-\mathrm{H}_{2}$ in the headspace every four laser shots in order to ensure a reproducible response (see ESI $\dagger$ ).

The evolution of the hydride signal intensity was followed as a function of the time, $\tau$, between the laser pump and NMR probe steps. This corresponds to following the change in amplitude of the longitudinal two-spin order term $\left(\mathrm{I}_{z} \mathrm{~S}_{z}\right)$ during the pump probe delay which, in the absence of NMR relaxation, is proportional to the concentration of 2 (Scheme 1). The signal

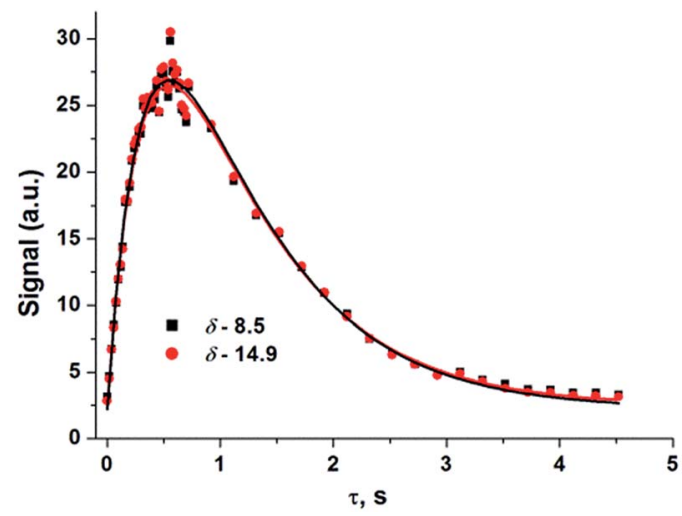

Fig. 3 Hydride signal integral values of $2 *$ versus $\tau$ (time) taken from a series of ${ }^{1} \mathrm{H}\left\{{ }^{31} \mathrm{P}\right\}$ NMR spectra that were recorded under 3.31 bar of $p$ $\mathrm{H}_{2}$ pressure. Coloured squares/circles are the experimental points while the lines show the fit according to eqn (2) where $R_{1}$ has been optimised as a linked parameter in a multiple dataset fit. Points were collected in random order.

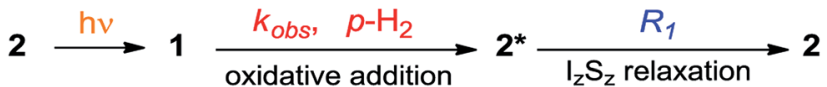

Scheme 2 Schematic diagram showing photodissociation of $\mathrm{H}_{2}$ from 2 , oxidative addition of $p-\mathrm{H}_{2}$ to 1 , and nuclear spin relaxation reactions of $2 *$

versus time profile (Fig. 3) shows that an exponential growth is followed by an exponential decay which ultimately restores the initial intensity. Such a build-up and decay profile is typical of that expected for two consecutive reactions where the first product is depleted as it takes part in the subsequent one. Here, the chemical process is the formation of $2 *$ by $p-\mathrm{H}_{2}$ addition to its photochemically formed precursor $\operatorname{IrI}(\mathrm{CO})\left(\mathrm{PPh}_{3}\right)_{2} 1$ and proceeds with a pseudo first order-rate constant $k_{\text {obs }}$. The subsequent decay is due to nuclear spin-lattice relaxation of the hyperpolarized NMR signal that proceeds with the first orderrate constant $R_{1}$ (Scheme 2). These experimental data can be fitted to the function in eqn $(2)^{28}$ to yield $k_{\text {obs }}$ of $2.1 \pm 0.2 \mathrm{~s}^{-1}$ for $\mathrm{H}_{2}$ oxidative addition under 3.31 bar of $p-\mathrm{H}_{2}$.

$$
\begin{aligned}
& \left(\frac{\mathrm{d}[\mathbf{2} *]}{\mathrm{d} t}\right)=k_{\text {obs }}[\mathbf{2}]-R_{1}\left[\mathbf{2}^{*}\right] \\
& {[\mathbf{2 *}]=[\mathbf{2}]_{0} \frac{k_{\text {obs }}}{R_{1}-k_{\text {obs }}} \times\left(\mathrm{e}^{-k_{\text {obs }} t}-\mathrm{e}^{-R_{1} t}\right)}
\end{aligned}
$$

The reformation of 2 follows pseudo-first-order kinetics under these conditions where $p-\mathrm{H}_{2}$ is in excess. We therefore varied the hydrogen pressure from 3 to 6 bar to extract $k_{2}$ from the resulting series of $k_{\text {obs }}$ values via the associated linear dependence analysis (Table 1 and Fig. 4).

The second order rate constant $k_{2}$, for the regeneration of 2 in the presence of hydrogen was determined from this analysis as $(3.26 \pm 0.42) \times 10^{2} \mathrm{M}^{-1} \mathrm{~s}^{-1}$ (with solubility of $\mathrm{H}_{2}$ taken as $2.9 \times 10^{-3} \mathrm{M} \mathrm{atm}^{-1}$ ) at $298 \mathrm{~K}^{29}$ In parallel to this NMR study, we also determined the kinetics of $\mathrm{H}_{2}$ addition to $\mathbf{1}$ by transient absorption UV-vis spectroscopy§ starting from photo-excitation (355 nm) of a $\mathrm{C}_{6} \mathrm{H}_{6}$ solution of 2 . Once more, the plot of $k_{\mathrm{obs}}$ against $\mathrm{H}_{2}$ pressure was linear with a corresponding second order rate constant of $(3.06 \pm 0.40) \times 10^{2} \mathrm{M}^{-1} \mathrm{~s}^{-1}$. Literature

Table $1 k_{\text {obs }}$ determined at different hydrogen pressures by photochemical pump-NMR probe

\begin{tabular}{ll}
\hline $\mathrm{H}_{2}$ pressure $^{a}$ bar & Hydride at $\delta-8.5 k_{\mathrm{obs}}{ }^{b}, \mathrm{~s}^{-1}$ \\
\hline 3.31 & $2.1 \pm 0.2$ \\
4.42 & $3.5 \pm 0.4$ \\
5.10 & $3.7 \pm 0.5$ \\
6.02 & $4.8 \pm 0.3$
\end{tabular}

${ }^{a}$ The amount of $p-\mathrm{H}_{2}$ at $26 \mathrm{~K}$ was calculated as $>99 \% .{ }^{5}{ }^{b}$ Polynomial fitting involved using $R_{1}$ (Scheme 2 and eqn (2)) as a shared parameter in a series of traces mapping $\mathrm{d}\left(2^{*}\right) / \mathrm{d} t$ as a function of $[p$ $\left.\mathrm{H}_{2}\right]$, the rate of relaxation of the double quantum term $\left(\mathrm{I}_{z} \mathrm{~S}_{z}\right)$ is not affected by the change in $\left[\mathrm{H}_{2}\right] .1 / R_{1}$ was determined to be $0.67 \pm 0.11$ $\mathrm{s}$. This value was validated by measuring the rate of relaxation of the $\mathrm{I}_{z} \mathrm{~S}_{z}$ term independently employing a different method (See ESI) $\dagger$. 


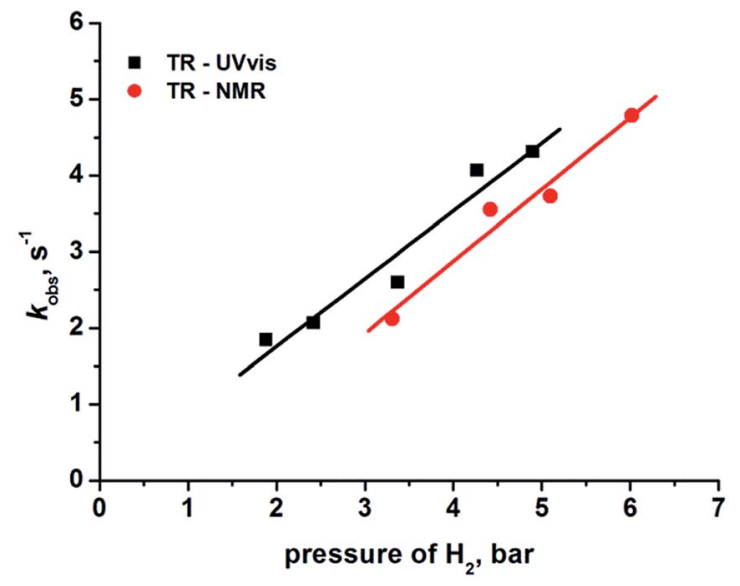

Fig. 4 Plots of pseudo-first-order rate constants $k_{\text {obs }}$ determined from the decay of the transients obtained by TR-NMR (black squares) and TR-UV-vis (red circles) after $355 \mathrm{~nm}$ excitation of complex 2 in benzene vs. the pressure of quenching gas $\left(\mathrm{H}_{2}\right)$. The corresponding lines of best fit are shown in black and red.

values for hydrogen uptake by 1 are reported as $430 \mathrm{M}^{-1} \mathrm{~s}^{-1}$ in chlorobenzene and $>10^{2} \mathrm{M}^{-1} \mathrm{~s}^{-1}$ in $\mathrm{C}_{6} \mathrm{D}_{6}$ solution at $30^{\circ} \mathrm{C}$, as determined by spectrophotometry ${ }^{12}$ and manometry ${ }^{10}$ techniques, respectively. These values are consistent with our TRNMR and TR-UV-vis measurements. In Fig. 4, we use the pressure of $\mathrm{H}_{2}$ as the $x$-axis quantity for UV/vis and NMR measurements. The underlying assumption is that 2 is formed with $100 \%$ spin-state purity. The non-zero intercept for the line through the NMR data may result from lower purity, but any such reduction has an insignificant effect on the rate $k_{2}$, because the rate is derived from the gradient of the lines..$^{21,30}$

The effect of temperature on the reactivity of 2 towards $\mathrm{H}_{2}$ was also tested. In order to do this, a set of similar photochemical pump-NMR probe experiments was undertaken at $315 \mathrm{~K}$ which gave a $k_{2}$ value of $(6.0 \pm 0.3) \times 10^{2} \mathrm{M}^{-1} \mathrm{~s}^{-1}$ from the corresponding plot of $k_{\mathrm{obs}} v s$. $\mathrm{H}_{2}$ pressure (See ESI $\dagger$ ); the gain in rate for this $17^{\circ}$ increase in temperature was $\sim 2$-fold. Additionally, the rate of the same reaction was measured as a function of temperature for a $\mathrm{C}_{6} \mathrm{D}_{6}$ solution of 2 under 4.42 bar of $\mathrm{H}_{2}$. The resulting activation parameters ${ }^{31}\left(\Delta H^{*}=42 \pm 1 \mathrm{~kJ} \mathrm{~mol}^{-1}, \Delta S^{\ddagger}=-53 \pm 1\right)$ (see ESI $\dagger$ ) were consistent with the values previously reported. ${ }^{10}$

We also obtained further insight into the mechanism of $\mathrm{H}_{2}$ addition to the metal centre using our pump-probe system. To clarify the mechanism, we exposed an optically dilute $\mathrm{C}_{6} \mathrm{D}_{6}$ solution of 2 under $p-\mathrm{H}_{2}$ atmosphere to 48 laser shots $(355 \mathrm{~nm}$, repetition frequency $10 \mathrm{~Hz}$, at $295 \mathrm{~K}, 3$ bar $p-\mathrm{H}_{2}$ ). The major detectable species was $2^{*}$ (Fig. 5) but by-products started to form after more than 32 laser shots. These arise from two additional photo-generated dihydride species $2 \mathrm{a}^{*}$ and $\mathbf{3}^{*}$. The splitting of the hydride peaks and their chemical shifts indicate that both of these species contain pairs of cis hydrides and cis phosphines (Fig. 5, see ESI $\dagger$ for $\delta$ and $J$ values). In 2a*, a bis phosphine complex, one hydride lies trans to carbonyl $(\delta-9.2)$ and the second $(\delta-11.5)$ lies trans to phosphorus. In $3^{*}$, one hydride ligand lies trans to iodine $(\delta-17.6)$ while the second $(\delta-11.2)$ is trans to phosphorus, but now an additional

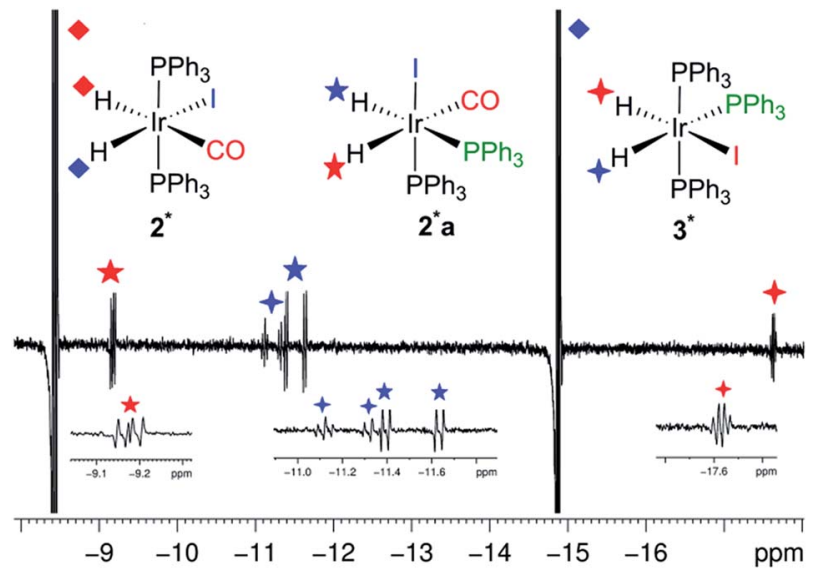

Fig. 5 Hydride region of the ${ }^{1} H$ NMR spectrum of a $C_{6} D_{6}$ solution of 2 exposed to 32 laser shots. The major peaks belong to 2* (diamonds); insets: same part of the spectrum magnified to observe the newly formed species $2 a^{*}$ and $3 *$.

phosphorus splitting confirms its identity as the ligand exchange product $\operatorname{Ir}(\mathrm{H})_{2}(\mathrm{I})\left(\mathrm{PPh}_{3}\right)_{3}$. Their relative signal strengths are 2 and $1 \%$ of those of $2^{*}$ respectively. Photoisomerization of square planar complexes is a well-known process. ${ }^{32}$ We therefore propose that following the formation of 1 by reductive elimination of $\mathrm{H}_{2}$ from $2^{*}$, secondary photolysis takes place to induce geometrical rearrangement and ligand dissociation in $\mathbf{1}$. The resulting photo-products react promptly with $p-\mathrm{H}_{2}$ giving rise to the observed enhanced signals of $2 \mathrm{a}^{*}$ and $3^{*}$. Their detection is completely suppressed by decreasing the temperature by $10^{\circ}(285 \mathrm{~K})$.

The identity of $3^{*}$ was also confirmed by trapping the intermediate with excess $\mathrm{PPh}_{3}$ (see ESI $\dagger$ ). The addition of 20 fold excess $\mathrm{PPh}_{3}$ to an optically dilute $\mathrm{C}_{6} \mathrm{D}_{6}$ solution of 2 resulted in the observation of $3^{*}$ at room temperature after addition of $p-\mathrm{H}_{2}$. The hyperpolarized hydride signals of $3 *$ could be made stronger by increasing the temperature to $50^{\circ} \mathrm{C}$. When the same solution was exposed to 32 laser shots, once again $2^{*}$ was the major species with $3^{*}$ being the only by-product present in solution. Under these conditions, the formation of $2 \mathbf{a}^{*}$ was prevented by the excess $\mathrm{PPh}_{3}$ which acted as a trap for any unsaturated species formed in solution. Interestingly, the minor isomer observed by thermal reaction of the chloride analogues exhibited a cis-cistrans structure that is not seen here..$^{23,33}$

When the temperature of an optically dilute solution of 2 under $p-\mathrm{H}_{2}$ was raised to $335 \mathrm{~K}$, thermal exchange was observed to result in small PHIP enhancements for the hydride resonances of 2 (SNR $\sim 40)$ in the absence of laser irradiation. In addition to these ${ }^{1} \mathrm{H}$ NMR signals, new enhanced hydride signals in the region $\delta-18$ to -22 were detected which remained visible by PHIP for several minutes (see ESI $\dagger$ ). These signals could also be accessed after multiple laser shots at lower temperatures ( $>16$ laser shots at $315 \mathrm{~K}$ ). The greater shielding of these hydride resonances is characteristic of those observed for dimers, such as $\mathrm{Rh}(\mathrm{H})_{2}\left(\mathrm{PPh}_{3}\right)_{2}(\mu-\mathrm{I})_{2} \mathrm{Rh}(\mathrm{CO})\left(\mathrm{PPh}_{3}\right) ;{ }^{20}$ we therefore assign these products to dimeric complexes with bridging iodine atoms (see ESI $\dagger)^{20}$ 


\section{Conclusions}

The observations that have been described here establish that the combination of in situ photochemistry and $p-\mathrm{H}_{2}$ derived signal amplification allows the quantification of $\mathrm{H}_{2}$ addition rates on a ms timescale by NMR spectroscopy. In this case, $\operatorname{IrI}(\mathrm{CO})\left(\mathrm{PPh}_{3}\right)_{2}$ (1) reacts with $p-\mathrm{H}_{2}$ at room temperature to generate $\operatorname{Ir}(\mathrm{H})_{2} \mathrm{I}(\mathrm{CO})\left(\mathrm{PPh}_{3}\right)_{2}$ (2) which is characterised by the PHIP-enhancement of its hydride resonances. While 2 is thermally stable to $\mathrm{H}_{2}$ loss at $298 \mathrm{~K}$, it is photoactive under $355 \mathrm{~nm}$ irradiation and in the presence of $p-\mathrm{H}_{2}$ PHIP-enhancement is observed. Because of the signal gain associated with PHIP, the accumulation of 2 could be easily followed between $50 \mathrm{~ms}$ and $1 \mathrm{~s}$ despite the inherently low sensitivity of NMR spectroscopy. Data analysis of the kinetics of formation of 2 from 1 as a function of $\mathrm{H}_{2}$ pressure and temperature yielded second order rate constants and activation parameters $\left(\right.$ e.g. $k_{2}=(3.26 \pm 0.42)$ $\left.\times 10^{2} \mathrm{M}^{-1} \mathrm{~s}^{-1}\right)$. This approach was validated by laser flash photolysis which yielded similar second order rate constants (e.g. $(3.06 \pm 0.40) \times 10^{2} \mathrm{M}^{-1} \mathrm{~s}^{-1}$ at $\left.298 \mathrm{~K}\right)$.

One benefit of this photochemical pump-NMR probe method is that we obtain high quality NMR spectra at the same time as measurement of rates of reaction, thus ensuring that we identify our products unambiguously. This method therefore contrasts with conventional laser flash photolysis where we rely on a broad UV/vis absorption of the reaction intermediate. Our $p-\mathrm{H}_{2}$ approach also brings the sensitivity of NMR spectroscopy into a similar range to time-resolved UV/vis absorption spectroscopy. The nearest comparable measurements by NMR spectroscopy have been made by photo-CIDNP ${ }^{34,35}$ or by stopped-flow NMR. ${ }^{36}$

Our measurements gave rate constants $k_{\text {obs }}$ in the range 1-10 $\mathrm{s}^{-1}$ and second-order rate constants $k_{2}$ of $c a .10^{3} \mathrm{M}^{-1} \mathrm{~s}^{-1}$. The evolution of the magnetic states that underpins this work has been described previously. ${ }^{7,9}$ If this method is to be used to monitor faster reactions, it is straightforward to reduce the delays between the laser pump and the NMR probe pulses. For reactions that occur so rapidly that dephasing of the zero quantum coherence has not occurred, a more detailed analysis is required, which will be published shortly.

It should be noted that photochemical pump-NMR probe spectroscopy could also be applied in a similar manner to other reactions involving dihydrogen. However, its applicability is even more general than this because $p-\mathrm{H}_{2}$ is only one of a growing number of molecules that can be prepared as a long-lived nuclear spin singlet (examples: dinitrogen, fumarate and stilbene). ${ }^{37}$ Hence, the reactivity of many such molecules could in principle be quantified analogously by probing the time evolution of appropriate ${ }^{1} \mathrm{H}$ or heteronuclear NMR signals.

\section{Acknowledgements}

We are grateful to EPSRC (grant EP/K022792/1) for funding, Simon Colebrooke for helpful discussions and Dr Soumya S. Roy for the thermal measurement of the $\mathrm{I}_{z} \mathrm{~S}_{z}$ states lifetime in 2 .

\section{Notes and references}

$\ddagger$ Data created during this research are available by request from the University of York Data Catalogue (http://dx.doi.org/10.15124 /282717d1-d7d9-428f-8b77b98b6a8b6f80).

$\S$ TR-UV-vis experiments were run in the presence of $\mathrm{H}_{2}$. The use of $p-\mathrm{H}_{2}$ does not change the results in this type of measurement.

1 R. Zhang and M. Newcomb, Acc. Chem. Res., 2008, 41, 468477.

2 J. M. Butler, M. W. George, J. R. Schoonover, D. M. Dattelbaum and T. J. Meyer, Coord. Chem. Rev., 2007, 251, 492-514.

3 P. Kukura, D. W. McCamant and R. A. Mathies, Annu. Rev. Phys. Chem., 2007, 58, 461-488.

4 R. J. D. Miller, Science, 2014, 343, 1108-1116.

5 R. A. Green, R. W. Adams, S. B. Duckett, R. E. Mewis, D. C. Williamson and G. G. R. Green, Prog. Nucl. Magn. Reson. Spectrosc., 2012, 67, 1-48.

6 S. B. Duckett and R. E. Mewis, Acc. Chem. Res., 2012, 45, 1247-1257.

7 O. Torres, B. Procacci, M. E. Halse, R. W. Adams, D. Blazina, S. B. Duckett, B. Eguillor, R. A. Green, R. N. Perutz and D. C. Williamson, J. Am. Chem. Soc., 2014, 136, 10124-10131.

8 C. R. Bowers and D. P. Weitekamp, J. Am. Chem. Soc., 1987, 109, 5541-5542.

9 J. Natterer and J. Bargon, Prog. Nucl. Magn. Reson. Spectrosc., 1997, 31, 293-315.

10 P. B. Chock and J. Halpern, J. Am. Chem. Soc., 1966, 88, 35113514.

11 L. Vaska and M. F. Werneke, Trans. N. Y. Acad. Sci., 1971, 33, 70-86.

12 L. Vaska and M. F. Werneke, Ann. N. Y. Acad. Sci., 1971, 172, 546-562.

13 A. L. Sargent and M. B. Hall, Inorg. Chem., 1992, 31, 317-321. 14 A. L. Sargent, M. B. Hall and M. F. Guest, J. Am. Chem. Soc., 1992, 114, 517-522.

15 G. L. Geoffroy, G. S. Hammond and H. B. Gray, J. Am. Chem. Soc., 1975, 97, 3933-3936.

16 L. Vaska, Acc. Chem. Res., 1968, 1, 335-344.

17 D. A. Wink and P. C. Ford, J. Am. Chem. Soc., 1985, 107, 55665567.

18 R. H. Schultz, J. Organomet. Chem., 2003, 688, 1-4.

19 C. J. Sleigh, S. B. Duckett and B. A. Messerle, Chem. Commun., 1996, 2395-2396.

20 S. A. Colebrooke, S. B. Duckett, J. A. B. Lohman and R. Eisenberg, Chem.-Eur. J., 2004, 10, 2459-2474.

21 P. Hubler, J. Bargon and S. J. Glaser, J. Chem. Phys., 2000, 113, 2056-2059.

22 S. K. Hasnip, S. B. Duckett, C. J. Sleigh, D. R. Taylor, G. K. Barlow and M. J. Taylor, Chem. Commun., 1999, 17171718.

23 S. K. Hasnip, S. A. Colebrooke, C. J. Sleigh, S. B. Duckett, D. R. Taylor, G. K. Barlow and M. J. Taylor, J. Chem. Soc., Dalton Trans., 2002, 743-751.

24 C. E. Johnson and R. Eisenberg, J. Am. Chem. Soc., 1985, 107, 3148-3160. 
25 M. C. Nicasio, R. N. Perutz and A. Tekkaya, Organometallics, 1998, 17, 5557-5564.

26 C. J. Jameson, in Multinuclear NMR, ed. J. Mason, Plenum Press, New York, 1987, pp. 89-131.

27 J. A. Aguilar, P. I. P. Elliott, J. Lopez-Serrano, R. W. Adams and S. B. Duckett, Chem. Commun., 2007, 1183-1185.

28 R. G. Wilkins, Kinetics and Mechanism of Reactions of Transition Metal Complexes, Wiley, VCH Weinheim, 1991.

29 M. V. Campian, R. N. Perutz, B. Procacci, R. J. Thatcher, O. Torres and A. C. Whitwood, J. Am. Chem. Soc., 2012, 134, 3480-3497.

30 D. Blazina, S. B. Duckett, T. K. Halstead, C. M. Kozak, R. J. K. Taylor, M. S. Anwar, J. A. Jones and H. A. Carteret, Magn. Reson. Chem., 2005, 43, 200-208.

31 We assume the solubility of $\mathrm{H}_{2}$ as constant over this temperature range in a sealed system.
32 S. Thies, H. Sell, C. Schutt, C. Bornholdt, C. Nather, F. Tuczek and R. Herges, J. Am. Chem. Soc., 2011, 133, 16243-16250.

33 S. K. Hasnip, S. B. Duckett, C. J. Sleigh, D. R. Taylor, G. K. Barlow and M. J. Taylor, Chem. Commun., 1999, 17171718.

34 A. S. Kiryutin, O. B. Morozova, L. T. Kuhn, A. V. Yurkovskaya and P. J. Hore, J. Phys. Chem. B, 2007, 111, 11221-11227.

35 S. Perrier, E. Mugeniwabagara, A. Kirsch-De Mesmaeker, P. J. Hore and M. Luhmer, J. Am. Chem. Soc., 2009, 131, 12458-12465.

36 M. D. Christianson, E. H. P. Tan and C. R. Landis, J. Am. Chem. Soc., 2010, 132, 11461-11463.

37 M. H. Levitt, Annu. Rev. Phys. Chem., 2012, 63, 89-105. 